\title{
Determinants of Socio-economic Empowerment of Married Women: Evidence from Ethiopia
}

\author{
Amanuel Disassa Abshoko, Nigatu Degu Terye, Aklilu Toma Shamenna \\ School of Mathematical and Statistical Sciences, Hawassa University, Hawassa, Ethiopia \\ Email address: \\ amanhu8@gmail.com (A. D. Abshoko),ndegu9@gmail.com (N. D. Terye), aketomy@gmail.com (A. T. Shamenna)
}

\section{To cite this article:}

Amanuel Disassa Abshoko, Nigatu Degu Terye, Aklilu Toma Shamenna. Determinants of Socio-economic Empowerment of Married Women: Evidence from Ethiopia. Humanities and Social Sciences. Vol. 4, No. 3, 2016, pp. 66-75. doi: 10.11648/j.hss.20160403.11

Received: February 15, 2016; Accepted: March 9, 2016; Published: June 7, 2016

\begin{abstract}
In Ethiopia, women's participation in their own matters and women's benefit from social, economic and political spheres is low. The study is attempted to identify the various possible determinants of women socio-economic empowerment using data collected from 384 households in the selected woredas of the Southern Nations, Nationalities and Peoples Regional State (SNNPR). A case-control household survey is conducted on randomly selected married women in study areas. Results of the study show that women's level of education, their employment status, their earning compared to husbands, exposure to media, place of residence, age at first marriage, family size and attitude towards wife beating are found to be the major determinants factors affecting women participation on their social and economic matters in a household. Therefore, the Concludes that policy designed at the micro level should be translated to solve the problem on the ground. Thus, considering their agency, women's empowerment at different levels might be realized. On the other hand, collecting clear statistical data and studying the different types of women's home based work and their empowerment and/or disempowerment effect might be areas of research that further have policy implications.
\end{abstract}

Keywords: Married Women, Empowerment, Multinomial Logistic Regression Model

\section{Introduction}

The dictionary meaning of the word empower is "to give somebody the power or authority to do something or to give somebody more control over their life or the Situation they are in". Kishor (2005), cited the works of Dixon (2008) and Mason (2006) who defined women's empowerment operationally as the degree of women's access to and control over material resources (including food, income, land and other forms of wealth) and social resources (including knowledge, power and prestige) within the family, in the community, and in the society at large. It is a multidimensional concept, which purports to measure a woman's ability to control resources, her ability to choose and control different outcomes, and above all to enhance her self-esteem.

Until recently, variables such as education and employment status were commonly used to capture empowerment and other related concepts such as women's autonomy and status. Their use is justified by the fact that they have strong positive correlation with the direct empowerment indicators. The number of decisions in which the woman participates and the number of situations in which a woman considers wife beating justifiable are indices of empowerment in this study.

In Ethiopia, women's participation in their own matters and women's benefit from social, economic and political spheres is low. Traditional, social and economic values constrain the rights of women and their opportunities to direct their own lives or participate in and contribute to community and national development (Bogalech and Mengistu, 2007). Gender imbalances exist in the division of labour, access to resources, distribution of income, and decision-making. In the history of Ethiopia, women are primarily tasked with food production and other household level activities. Rights to land, credit, and other productive resources are difficult for women to attain.

In 1993, the government of the Federal Democratic 
Republic of Ethiopia (FDRE) issued the National Ethiopian Policy on Women and granted equal rights for women under the constitution. Moreover, a new family law was recently instituted focusing on the advancement of women, affirmative action, and provision for higher education, employment and promotion in the workplace (FDRE, 1993).

Different studies indicated the lower status of women with regard to decision making in developing countries in general and in Ethiopia in particular (Almaz, 2009; Hirut, 2012; Mukuria et al., 2012). Lack of access to productive resources such as land; lack of access to education, employment opportunities, basic health services, and protection of basic human rights; violence and harmful traditional practices are some of the indicators of the socioeconomic marginalization of women in the country. Employment is one aspect of social life in which gender roles and relationships emerge. Employment can be a source of empowerment for both women and men, especially if they are in control of the income they generate. Employment is one aspect of social life in which gender roles and relationships emerge. Employment can be a source of empowerment for both women and men, especially if they are in control of the income they generate.

The 2011 EDHS assess women's decision-making autonomy; in health care, making major household purchases, and visits to family or relatives and found that women are considered to participate in a decision if they usually make that decision alone or jointly with their husbands. $13 \%$ of currently married women make their own decisions on their own health care, while one woman of every four said that her husband mainly makes such decisions. Thus the purpose of this study is to carry out an indepth investigation of gender differences on basic socio economic and demographic characteristics and status of women empowerment in the study area.

Gender gap between men and women in socio-economic indicators has negative impact on the overall development of the country in general and on demographic and health outcomes of individuals in particular. Failure to address this issue will have serious consequences for the economy and society of a country. So, this study attempts to examine the determinants of women empowerment in Dale and Wondogenet woredas and to provide empirical information for policy makers.

The general objective of this study is to identify and describe the various possible determinants of women empowerment in the selected woredas. Specific objectives are:

- To assess the overall situation of married women in the study area.

- To describe the extent of the variation in women empowerment between rural and urban parts in the selected woredas.

- To identify the type of activities that married women perform in their daily life for their survival.

- To provide relevant recommendations for policy makers and program managers.

\section{Methods}

For the purpose of this study data is collected on a randomly selected married women living in Wondo Genet and Dale woredas; which are situated in the Southern Nations, Nationalities and Peoples' Region (SNNPR) of Ethiopia. Part of the Sidama Zone located in the Great Rift Valley.

Based on the 2007 Census conducted by the CSA, Wondo Genet woreda has a total population of 155,715 , of whom 79,664 are men and 76,051 women; 23,125 or $14.85 \%$ of its population are urban dwellers. Dale is another woreda. Based on the 2007 Census conducted by the CSA, this woreda has a total population of 242,658 , of whom 122,918 are men and 119,740 women; 30,348 or $12.51 \%$ of its population are urban dwellers. Majority of the inhabitants are followers of Protestant religion, succeeding Ethiopian Orthodox Christianity, Muslim, Catholic, and traditional religions.

A case-control household survey is conducted among randomly selected married women in study areas. Random samples of 384 households are selected such that mothers from each household are considered as a sampling population for the purpose of this study.

\subsection{Variables Under the Study}

The dependent and independent variables that are considered to affect the women empowerment are selected based on experiences from the available similar studies and the available data on the area.

\subsection{The Response Variable}

The response variable of this study is the socio-economic empowerment of married women in the study area. For the purpose of this study, empowerment of a woman is measured as a multinomial random variable "only a husband makes all decisions" or "Both wife and husband make decisions" and "only wives make a decision". Therefore, the outcome for the $i^{\text {th }}$ individual is represented by a random variable $Y_{i}$ with three possible values. Therefore, $\mathrm{Y}_{\mathrm{i}}$ is a multinomial distributed random variable.

\subsection{Explanatory Variables/Factors}

Based on the reviewed literatures, some of the common Demographic and Socioeconomic predictors that are expected to influence the empowerment status of women are: Attitude towards wife beating

Age at marriage

Women's exposure to media

Educational status of the women

Educational status of her partner

Family size

Employment status of the women

Place of residence

Access of public services

Women's income relative to her husband

Attitude towards wife beating 


\subsection{Method of Data Analysis}

\subsubsection{Multinomial Logistic Regression}

Generalizing to a multinomial dependent variable requires us to make some notational adaptations. Let $J$ represent the number of discrete categories of the dependent variable, where $J>2$. Now, consider random variable $Z$ that can take on one of $J$ possible values. If each observation is independent, then each $Z_{i}$ is a multinomial random variable. Once again, we aggregate the data in to populations each of which represents one unique combination of independent variable settings. As with the binomial logistic regression model, the column vector $n$ contains elements $n_{i}$ which represent the number of observations in population $i$, and such that

$\sum_{i=i}^{N} n_{i}=M$, the total sample size.

Since each observation records one of J possible values for the dependent variable, $Z$, let $\mathrm{y}$ be a matrix with $\mathrm{N}$ rows (one for each population) and $J-1$ column. Note that if $J=2$ this reduces to the column vector used in the binomial logistic regression model. $\mathrm{F}$ or each population, $\mathrm{y}_{\mathrm{ij}}$ represents the observed counts of the $j^{\text {th }}$ value of $Z_{\mathrm{i}}$. Similarly, $\boldsymbol{\pi}$ is a matrix of the same dimensions as $\boldsymbol{y}$ where each element $\pi_{i j}$ is the probability of observing the $j^{\text {th }}$ value of the dependent variable for any given observation in the $i^{\text {th }}$ population.

The design matrix of independent variables, $\boldsymbol{X}$, remains the same- it contains $N$ rows and $K+1$ columns where $K$ is the number of independent variables and the first element of each row, $\mathrm{x}_{\mathrm{i} 0}=1$, the intercept. Let $\beta$ be a matrix with $K+1$ rows and $J-1$ columns, such that each element $\beta k_{j}$ contains the parameter estimate for the $k^{\text {th }}$ covariate and the $j^{\text {th }}$ value of the dependent variable.

For the multinomial logistic regression model, we equate the linear component to the log of the odds of a $j^{\text {th }}$ observation compared to the $J^{\text {th }}$ observation. That is, we will consider the $J^{\text {th }}$ category to be the omitted or baseline category, where logits of the first $J-1$ categories are constructed with the baseline category in the denominator.

$$
\begin{gathered}
\log \left(\frac{\pi_{i j}}{\pi_{i J}}\right)=\log \left(\frac{\pi_{i j}}{1-\sum_{J-1}^{J-1} \pi_{i j}}\right)=\sum_{K=0}^{K} x_{i k} \beta_{k j}, \\
\text { for } i=1,2, \ldots, N \text { and } j=1,2, \ldots, J-1
\end{gathered}
$$

Solving for $\pi_{i j}$ we have,

$$
\begin{aligned}
\pi_{i j} & =\frac{e^{\sum_{K=0}^{K} x_{i k} \beta_{k j}}}{1+\sum_{j-1}^{J-1} e^{\sum_{K=0}^{K} x_{i k} \beta_{k j}}} \mathrm{j}<\mathrm{J} \\
\pi_{i j} & =\frac{1}{1+\sum_{j-1}^{J-1} e^{\sum_{K=0}^{K} x_{i k} \beta_{k j}}}
\end{aligned}
$$

\subsubsection{Parameter Estimation}

For each population, the dependent variable follows a multinomial distribution with $\mathrm{J}$ levels. Thus, the joint probability density function is:

$$
f(y \backslash \beta)=\prod_{i=1}^{N}\left(\frac{n_{i} !}{\prod_{j=1}^{J} y_{i j} !} \cdot \prod_{j=1}^{J} \pi_{i j} y_{i j}\right)
$$

The likelihood function is algebraically equivalent to Eq. 3 , the only difference being that the likelihood function expresses the unknown values of in terms of known fixed constant values for $y$. Since we want to maximize Eq. 3 with respect to, the factorial terms that do not contain any of the $\pi_{i j}$ terms can be treated as constants.

The log likelihood function of multinomial logistic regression model is given by:

$$
\sum_{i=1}^{N} \sum_{j=1}^{J-1}\left(y_{i j} \sum_{k=0}^{k} x_{i k} \beta_{k j}\right)-n_{i} \log \left(1+\sum_{j=1}^{J-1} e^{\sum_{k=0}^{k} x_{j k} \beta_{k j}}\right)
$$

\subsection{Checking Model Adequacy}

Once a model has been fitted to a given data, it is a good statistical practice to check the adequacy of the model, which is essentially checking the agreement between the observed and fitted values under the model. If the agreement between the observations and the corresponding fitted values is good, the model may be acceptable. If not, the current form of the model will certainly not be acceptable and the model will need to be revised. This aspect of the adequacy of a model is widely referred to as goodness of fit.

There are several statistical measures by which the discrepancy between observed data and fitted values under an assumed model can be assessed. Of these, the most widely used is based on the likelihood function for the assumed model. The basic concept underlying this procedure is to compare the maximum likelihood under an assumed model with that of a baseline model. Let $\hat{L}_{c}$ be the maximized likelihood under the current model. This statistic cannot be used on its own to assess the lack of fit of the current model unless compared with a corresponding statistic of an alternative baseline model for the same data. This latter model is taken to be a model that fits the data perfectly. Such a model will have the same number of unknown parameters as there are observations. The model is termed the full or saturated model and the maximized likelihood under it is denoted by $\hat{L}_{f}$. The saturated model does not condense the information in the bulk of data into a simple summary, as it is not parsimonious. However, the maximum likelihood under this model is an intuitively appealing reference by which a corresponding value of a given model can be compared to assess the adequacy of the given model. Let the statistic D, be defined as

$$
D=-2 \log \left(\hat{\mathrm{L}}_{\mathrm{c}} / \hat{\mathrm{L}}_{\mathrm{f}}\right)=-2\left[\log \hat{\mathrm{L}}_{\mathrm{c}}-\log \hat{\mathrm{L}}_{\mathrm{f}}\right]
$$

Large values of $\mathrm{D}$ are encountered when $\hat{L}_{c}$ is small relative to $\hat{L}_{f}$, indicating that the current model is a poor one. On the other hand, small values of $\mathrm{D}$ are obtained when $\hat{L}_{c}$ is similar to $\hat{L}_{f}$, indicating that the current model is a good one. The statistic D therefore measures the extent to which the current model deviates from the full model and is termed the 
deviance. This statistic is a useful measure for detecting lack of fit of a given logistic regression model for grouped binary data. However, it proves to be uninformative for assessing lack of fit of a model for individual binary data (Collet, 1991), indeed this is the case for the data in this study. An alternative method for checking goodness of fit for individual binary data has been proposed by Hosmer and Lemeshow (2000). The outline of this procedure is briefly described in the following subsection.

\subsection{The Hosmer-Lemeshow Test Procedure}

The test statistic for this test procedure is formulated under the null hypotheses that the model fits the data, and the alternative is that the model does not fit the data. The test statistic is constructed by grouping the data set into roughly 10 (g) groups. The groups are formed by ordering the existing data by the level of their predicted probabilities. So the data are first ordered from least likely to have the event to most likely for the event. Then g (often 10) roughly equal sized groups are formed. From each group the observed and expected numbers of events are computed for each group. The test statistic is

$$
\hat{\mathrm{C}}=\sum_{\mathrm{K}=1}^{\mathrm{g}} \frac{\left(0_{\mathrm{k}}-\mathrm{E}_{\mathrm{k}}\right)^{2}}{\mathrm{v}_{\mathrm{k}}}
$$

Where, $\mathrm{O}_{\mathrm{k}}$ and $\mathrm{E}_{\mathrm{k}}$ are the observed and expected number of events in the $\mathrm{k}^{\text {th }}$ group, and $\mathrm{v}_{\mathrm{k}}$ is a variance correction factor for the $\mathrm{k}^{\text {th }}$ group. If the observed number of events differs from what is expected by the model, the statistic $\hat{C}$ will be large and there will be evidence against the null hypothesis. This statistic has an approximate chi-squared distribution with $(g-2)$ degrees of freedom.

\subsection{Testing Significance of Model Parameters and the Effect of Adding Terms}

In order to test concerning the model parameters we need to know the distribution of the estimates. Under certain regularity conditions the maximum likelihood estimates have an asymptotic multivariate normal distribution with expected value equal to the true parameters. A test procedure that uses this general result is the Wald test, which can be used to test individual as well as several parameters at a time. The test procedure is as follows. Suppose it is desired to test the significance of the $\mathrm{j}^{\text {th }}$ parameter, so that the null hypothesis can be stated as:

$\mathrm{H}_{0}: \beta_{\mathrm{j}}=0$ The Wald test statistic for this hypothesis is

$$
Z=\frac{\hat{\beta}_{j}}{\sqrt{\operatorname{Va} r\left(\hat{\beta}_{j}\right)}}
$$

This statistic has approximately a standard normal distribution in large samples. Equivalently, the square of this statistic has an approximate chi-squared distribution with one degrees of freedom and this is the usual formulation of this statistical procedure. In addition this test statistic can be used to construct a confidence interval for $\beta_{\mathrm{j}}$. An approximate $100(1-\alpha) \%$ confidence interval for the true parameter is

$$
\hat{\beta}_{j} \pm Z_{\alpha / 2} \sqrt{\operatorname{Vâr}\left(\hat{\beta}_{j}\right)}
$$

Where $Z_{\alpha / 2}$ is the normal critical value for a two-sided test of size $\alpha$. Confidence intervals for effects in the logit scale can be translated into confidence intervals for odds ratios by exponentiation of the boundaries.

Now consider a more general situation where it is desired to assess the importance of adding explanatory variables in a given model. In the previous section, the deviance has not been considered as a good measure of lack of fit of a model for individual binary data. However, this statistic can be used to compare two nested models for grouped as well as ungrouped binary data. When one model contains terms that are additional to those in another, the two models are said to be nested. The difference in the deviances of two nested models measures the extent to which the additional terms improve the fit of the model to the observed response variable.

\section{Outliers and Influential Cases}

The observed response for a few of the cases may not seem to correspond to the model fitted to the bulk of the data. Cases that do not follow the same model as the rest of the data are called outliers, and identifying these cases can be useful. Single cases or small groups of cases can strongly influence the fit of logistic regression model. The most useful and important method of perturbing the data is deleting the cases from the data one at a time. Cases whose removal causes major changes in the analysis are called influential (Sanford, 2005).

DFBETA (S) is a diagnostic measure which measures the change in the logit Coefficients for a given variable when a case is dropped. If DFBETAs is less than unity it implies no specific impact of an observation on the coefficient of a particular predictor variable, while DFBETA of a case is greater than 1.0, is considered as potential outlier.

Cook's distance is a measure of the influence of a case. It is a measure of how much the residual of all cases would change if a particular case were excluded from the computation of the regression coefficients. Cook's distance less than unity shows that an observation had no overall impact on the estimated vector of regression coefficients $\beta$.

Analog of Cook's influence statistics of a case greater than 1.0 indicates that a potential outlier, while the value of the leverage statistic less than one shows that no subject has a substantial large impact on the predicted values of a model.

Multicollinearity: refers to a situation where there is either an exact or approximately exact linear relationship among the predictor variables. In other words Multicolinirety is the degree of redundancy or overlap among explanatory variables. The existence of multicollinearity makes it hard to get coefficient estimates with small standard error (Gujarati, 2004). 


\section{Results and Discussion}

The aim of this study is to identify the factors which are associated with socio-economic empowerment of women and to examine the extent of variation between-urban/rural in terms of their status in the study area. The total number of married women in the study area is expected to be 64,560 . For the purpose of this study data is collected on a random sample of 384 married women.

\subsection{Characteristics of Women in the Study Area:- Descriptive Analysis}

The descriptive results of the socio-economic and demographic characteristics of married women in Dale and Wondogenet woredas such as; Wealth status of the women, Attitude towards wife beating, Age at marriage, Women's exposure to media, Educational status of the women, Educational status of her partner, Family size, access to electric power, Employment status of the women and Place of residence are presented in Table 1, 2 and Table 3.

According to Table 1, the average current age of women is around 30 years old whereas the average age of their partner is around 37. On the other hand, the average number of family size is 6 . Similarly the average age of women at marriage is around 19 years old.

Table 1. Descriptive Results for the Quantitative Variables.

\begin{tabular}{|c|c|c|c|c|}
\hline & Minimum & Maximum & Mean & Std. Deviation \\
\hline Number of household members & 1 & 14 & 6.09 & 2.027 \\
\hline Age at marriage (in years) & 12 & 38 & 19.36 & 3.361 \\
\hline Women's age (in years) & 17 & 49 & 30.28 & 6.593 \\
\hline Husband/partner's age (in years) & 15 & 95 & 37.43 & 10.738 \\
\hline
\end{tabular}

Table 2 shows the distribution of women in the study area varies with respect to their place of residence. Regarding to this majority of the women reside to the rural areas (94.6 percent). Whereas, the smaller proportion (5.4 percent) reside to the urban areas. Concerning their religious practices, the majority (65.2 percent) are followers of Protestantism following the orthodox Christians (12.6 percent). Similarly with respect to their educational status, the majority $(64.5$ percent) are none educated and only 2 percent of them has an educational status of above secondary school.

Regarding their access to media, majority (66.2\% percent) have no any access to media; while the smaller 9.7 percent have the access. According to the results of Table below, majority of married women in the study area (49.9 percent) are still in the category of a poor wealth index. Among a random sample of 384 respondents the majorities (60.9 percent) are also still unemployed and only 39 percent $s$ are employed.

Husband's/Partner's educational status is also another variable which is expected to affect women empowerment in the study area. Regarding to this, the majority (54.3 percent) of the partners have an educational status of primary following the illiterate ( 37 percent). Income of the women relative to her husband is another important characteristic of women in the study area. Regarding to this the majority (32.7 percent) of earn less than their husband. While the smaller proportion (2.2 percent) earn equally with their husband.

Regarding access to electric power, majority of the households in the study area have an access to electric power (79.6 percent) and only 18.1 percent of the households have this access. As Table 6 shows majority of the decisions regarding household purchase are made by jointly $(47.7$ percent) following the husband himself alone (43.1 percent). Regarding to the decisions about what to do with money in the household, the majority is made by jointly even though 30.2 percent of the decisions are made by the husband alone.

The attitude towards wife beating is a common traditional practice facing married women in the study area. Accordingly, the majority ( 62.8 percent) of married women justified beating with their husband because of going to somewhere without telling to him and 63.8 percent justified a similar problem due to argue with their husband also 67.7 percent of married women justified beating due to burning of food.

Table 2. Distribution of socio-economic and demographic characteristics of married women in Dale and Wondogenet Woredas (Sidama Zone, SNNP).

\begin{tabular}{llll}
\hline Variables & Categories & Frequency & Percent \\
\hline Type of place of residence & Urban & 20 & 5.4 \\
& Rural & 363 & 94.6 \\
& Orthodox & 48 & 12.6 \\
& Catholic & 14 & 3.7 \\
Religion & Protestant & 250 & 65.2 \\
& Muslim & 44 & 11.8 \\
& Traditional & 6 & 1.8 \\
Educational Status of the Women & Other & 18 & 4.9 \\
& No education & 247 & 64.5 \\
Access to Mass media & Primary & 128 & 33.5 \\
\hline
\end{tabular}




\begin{tabular}{|c|c|c|c|}
\hline Variables & Categories & Frequency & Percent \\
\hline \multirow{4}{*}{ Wealth index } & Yes & 37 & 9.7 \\
\hline & Poor & 191 & 49.9 \\
\hline & Middle & 153 & 40.1 \\
\hline & Rich & 16 & 10.1 \\
\hline \multirow{3}{*}{ Husband/partner's education level } & No education & 142 & 37.0 \\
\hline & Primary & 208 & 54.3 \\
\hline & Secondary and above & 29 & 7.8 \\
\hline \multirow{3}{*}{ Husband/partner's occupation type } & Jobless & 0 & 0 \\
\hline & Agricultural & 300 & 78.2 \\
\hline & Non agricultural & 82 & 21.6 \\
\hline \multirow{2}{*}{ Women 's Employment status } & No & 233 & 60.9 \\
\hline & Yes & 149 & 39.0 \\
\hline \multirow{3}{*}{ Person who usually decides on women's health care } & Women alone & 45 & 11.8 \\
\hline & Women and husband/partner & 193 & 50.5 \\
\hline & Husband/partner alone & 120 & 31.4 \\
\hline
\end{tabular}

Table 3. Distribution of socio-economic and demographic characteristics of married women in Dale and Wondogenet Woredas (Sidama Zone, SNNP).

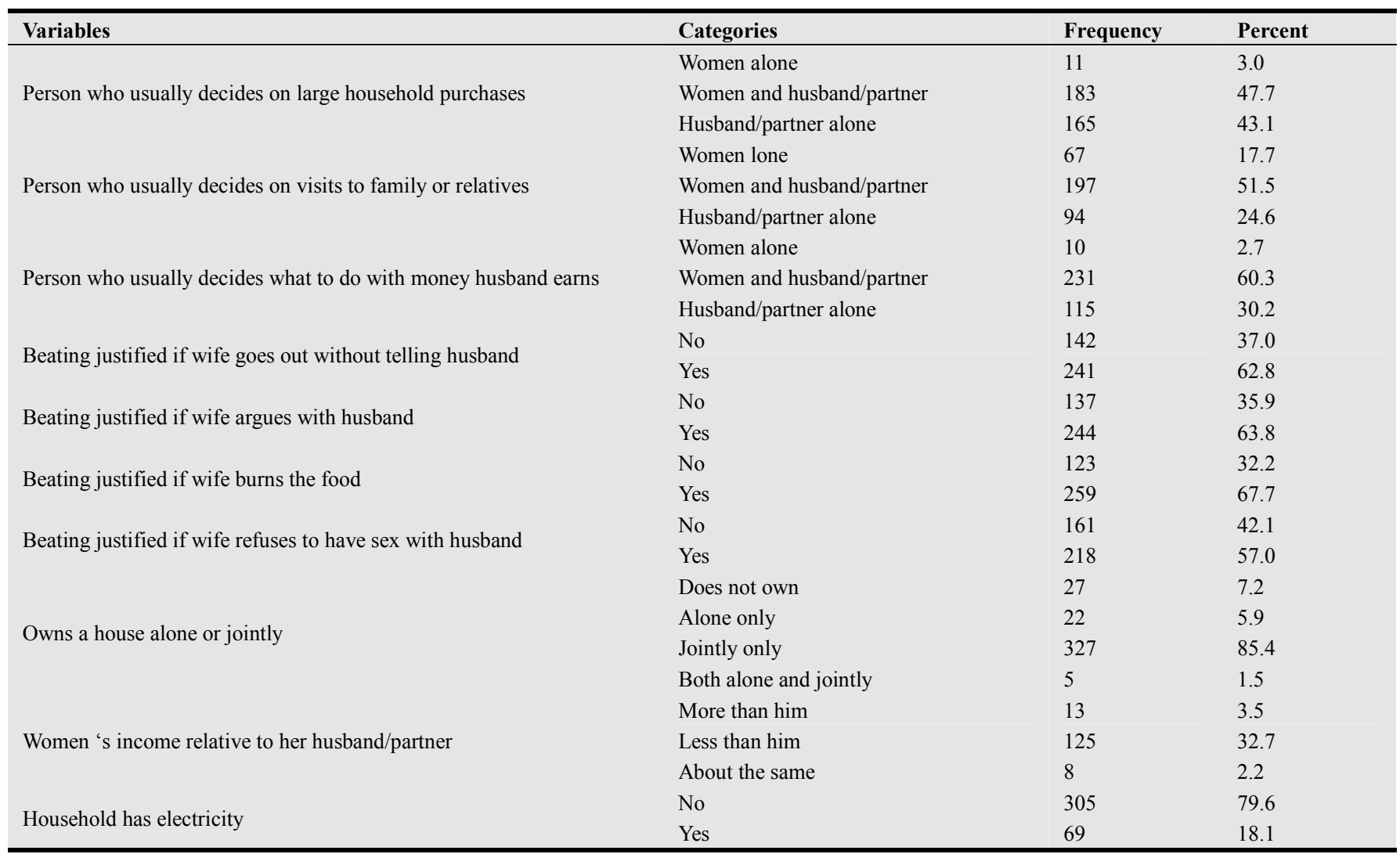

\subsection{Logistic Regression Results}

The Multiple Logistic Regression Model is fitted using both continuous and categorical (covariate) predictor variables. The results are presented in table 4 . The result shows that seven of the predictor variables are significantly associated with women empowerment in the study area.

\subsection{Assessment of Goodness of Fit of the Model}

Goodness-of-fit statistics assess the fit of a logistic model against actual outcomes. The statistical significance of individual regression coefficients is tested using the Wald chi-square statistic (Table 4). According to the results, place of residence, age of a woman, place of residence, women educational status, family size, access to media, age at marriage, employment status of the woman and Income a women all in categories are significant predictors for women empowerment in the study area $(p<0.05)$.

For categorical data, after we fit the logistic model, it is necessary to see the appropriateness', adequacy and usefulness of the fitted model. To overcome this we have several techniques. The most commonly used techniques are Pearson's Chi-square, the likelihood ratio tests (LRT), Hosmer and Lemeshow Goodness of fit Test and the Wald tests are the most widely used methods. 


\subsection{Likelihood-Ratio Test}

The result presented in table 3 shows that a likelihood ratio test statistic $G^{2}=1171$ which is distributed as chi-square with 50 degree of freedom. The tabulated value was $x_{0.05}^{2}(50)=331.159$. Since, $G^{2}>x_{0.05}^{2}(50)$, we reject the null hypothesis and conclude that at least one of the predictors variables was significantly related with women empowerment.

Table 4. Model Fitting Information.

\begin{tabular}{lllll}
\hline \multirow{2}{*}{ Model } & Model Fitting Criteria & \multicolumn{3}{l}{ Likelihood Ratio Tests } \\
\cline { 2 - 5 } & $\mathbf{- 2}$ Log Likelihood & Chi Square & df & Sig. \\
\hline Intercept Only & 1502 & & & \\
Final & 1171 & 331.159 & 50 & .000 \\
\hline
\end{tabular}

The Nagelkerke $\mathrm{R}$ square was 38.7 percent indicating that explanatory variables were useful in predicting the women empowerment. But, it doesn't give the meaning of variance explained as in linear regressions (Long, 1997, pp. 104-109;
Menard, 2000). Furthermore, it doesn't correspond to predictive efficiency or can be tested in an inferential framework (Menard, 2000).

Table 5. Pseudo R-Square.

\begin{tabular}{ll}
\hline Cox and Snell & .320 \\
Nagelkerke & .387 \\
McFadden & .220 \\
\hline
\end{tabular}

\subsection{Validations of Predicted Probabilities}

The degree to which predicted probabilities agree with actual outcomes is expressed as a classification table. Classification table documents the validity of predicted probabilities (Table 3). According to Table 3, the magnitude of sensitivity is 63.1 percent as compared to that of specificity (89.9 percent). Sensitivity measures the proportion of correctly classified events whereas specificity measures the proportion of correctly classified nonevents. The overall correct prediction is 66.9 percent which is an improvement over the chance level.

Table 6. Classification Table of Model with Predictor Variables for Women Empowerment.

\begin{tabular}{lllll}
\hline \multirow{2}{*}{ Observed } & Predicted & & & \\
\cline { 2 - 6 } & Women alone & Women and husband/partner & Husband/partner alone & Percent Correct \\
\hline Women alone & 53 & 29 & 2 & $63.1 \%$ \\
Women and husband/partner & 16 & 483 & 39 & $89.8 \%$ \\
Husband/partner alone & 12 & 186 & 39 & $16.5 \%$ \\
Overall Percentage & $9.4 \%$ & $81.3 \%$ & $9.3 \%$ & $66.9 \%$ \\
\hline
\end{tabular}

\subsection{Interpretation of Logistic Regression Coefficients}

A multiple logistic model was fitted to the data to test the research hypothesis regarding the relationship between the likelihood that woman empowerment is related with place of residence, current age of a woman, woman's age at marriage, attitude towards wife beating, woman educational status, educational status of husband/partner, family size, access to media, woman's income relative to her husband, access to electric power, employment status of a woman.

According to the model, the log of the odds of a woman to make decision alone instead of her husband is negatively related with age of the women $(p<0.05)$. Indicating that the older the woman the less likely to make a decision alone. That is a one unit increase in woman's age decreases the likelihood of making decision alone by 0.143 .

The result in table 7 also presents the woman empowerment is also positively related with their age at marriage. Indicating that the older the woman's age at marriage the more likely to make a decision instead of her husband. That is a one unit increase in age at marriage increase the likelihood of making decision by women 0.065 .

Place of residence is also significantly associated with women empowerment. The likelihood of women makes a decision instead of her husband alone for those in urban areas increases by 26.6 percent than those in rural areas. Similarly, as Table below shows, Educational status of women is also significantly associated with their empowerment $(\mathrm{P}<0.001)$. Accordingly, women who are not educated are 0.607 times less to make a decision than those who have secondary and above educational level.

The likelihood of women to make a decision instead of their husband alone is positively associated with access to media $(\mathrm{p}<0.05)$. Women who have the access are 2.790 times more likely to make a self decision compared to those who have no this access. As Table 7 shows, the problem of empowerment is also negatively associated with family size $(p<0.05)$. Accordingly, a one unit increase in family size increases the likelihood of women to making a self decision by 0.224 keeping the other variables constant.

Income of women relative to their husband is also significantly associated with their empowerment on decision making $(\mathrm{p}<0.05)$. Concerning to this, women who have greater income are 0.733 times more likely to make a self decision instead of their husband compared to those with smaller income.

Women's empowerment is also significantly associated with their beating justification $(p<0.05)$. Regarding to this those are not justified are times 1.036 more likely to make a self decision compared to those who are keeping the other variables constant. 
Table 7. Multinomial Logistic Regression Results for Women Empowerment.

\begin{tabular}{|c|c|c|c|c|c|c|c|c|c|c|c|c|}
\hline \multirow{2}{*}{\multicolumn{3}{|c|}{$\begin{array}{l}\text { Person who usually decides on a socio-economic } \\
\text { issues in the household }\end{array}$}} & \multirow{3}{*}{$\beta$} & \multirow{3}{*}{ Std. Error } & \multirow{3}{*}{ Wald } & \multirow{3}{*}{ df } & \multirow{3}{*}{ Sig. } & \multirow{3}{*}{$\operatorname{Exp}(\beta)$} & \multicolumn{4}{|c|}{ 95\% Confidence Interval for $\operatorname{Exp}(\beta)$} \\
\hline & & & & & & & & & \multirow{2}{*}{\multicolumn{2}{|c|}{ Lower Bound }} & \multirow{2}{*}{\multicolumn{2}{|c|}{ Upper Bound }} \\
\hline & \multicolumn{2}{|c|}{ Covariates } & & & & & & & & & & \\
\hline & \multicolumn{2}{|c|}{ Intercept } & -.143 & 1.099 & .017 & 1 & .896 & & & & & \\
\hline & \multicolumn{2}{|c|}{ Age of the woman } & -.043 & .010 & 18.385 & 1 & $.000 *$ & .958 & 940 & & .977 & \\
\hline & \multicolumn{2}{|c|}{ amily size } & -.224 & .027 & 66.398 & 1 & $.000^{*}$ & .800 & .758 & & .844 & \\
\hline & \multicolumn{2}{|c|}{ Age at marriage } & .065 & .008 & 61.147 & 1 & $.000^{*}$ & 1.067 & 1.050 & & 1.084 & \\
\hline & Plac & of residence & & & & & & & & & & \\
\hline & Urba & & .236 & .104 & 5.108 & 1 & $.024 *$ & 1.266 & 1.032 & & 1.553 & \\
\hline & Rura & (Ref) & $0^{\mathrm{b}}$ & . & . & 0 & . & . & . & & . & \\
\hline & Justi & ication of beating & & & & & & & & & & \\
\hline & No & & 1.036 & .355 & 8.492 & 1 & $.004 *$ & 2.818 & 1.404 & & 5.655 & \\
\hline & Yes & Ref) & $0^{\mathrm{b}}$ & . & . & 0 & . & . & - & & . & \\
\hline & Won & en's educational status & & & & & & & & & & \\
\hline & No e & lucation & -.607 & .194 & 9.820 & 1 & $.002 *$ & .545 & .373 & & .797 & \\
\hline & Prim & & -.211 & .185 & 1.298 & 1 & .255 & .810 & .564 & & 1.164 & \\
\hline & Seco & idary and above (Ref) & $0^{\mathrm{b}}$ & . & . & 0 & . & . & . & & . & \\
\hline & Acc & is to media & & & & & & & & & & \\
\hline & No & & 2.652 & .758 & 12.240 & 1 & $.000^{*}$ & 14.186 & 3.211 & & 62.681 & \\
\hline Women & Som & times & 2.131 & .747 & 8.130 & 1 & $.004 *$ & 8.422 & 1.947 & & 36.433 & \\
\hline & Yes & Ref) & $0^{\mathrm{b}}$ & . & . & 0 & . & . & . & & . & \\
\hline & Wea & h index & & & & & & & & & & \\
\hline & Rich & & -.308 & .088 & 12.424 & 1 & $.000^{*}$ & .735 & .619 & & .872 & \\
\hline & Med & & -.145 & .085 & 2.904 & 1 & .088 & .865 & .732 & & 1.022 & \\
\hline & Poor & (Ref) & $0^{\mathrm{b}}$ & . & . & 0 & · & . & . & & . & \\
\hline & Educ & ational status of Husband/partner & & & & & & & & & & \\
\hline & No e & lucation & -.063 & .142 & .196 & 1 & .658 & .939 & .711 & & 1.240 & \\
\hline & Prim & & -.045 & .137 & .107 & 1 & .744 & .956 & .732 & & 1.250 & \\
\hline & Seco & idary and above (Ref) & $0^{\mathrm{b}}$ & . & . & 0 & . & . & . & & . & \\
\hline & Won & en's employment status & & & & & & & & & & \\
\hline & Yes & & -1.088 & .075 & 211.233 & 1 & $.000 *$ & .337 & .291 & & .390 & \\
\hline & No ( & & $0^{\mathrm{b}}$ & . & . & 0 & . & . & . & & . & \\
\hline & $\begin{array}{l}\text { Won } \\
\text { husb }\end{array}$ & $\begin{array}{l}\text { en's income relative to her } \\
\text { and }\end{array}$ & & & & & & & & & & \\
\hline & Grea & & .733 & .137 & 28.489 & 1 & $.000^{*}$ & 2.080 & 1.590 & & 2.723 & \\
\hline & Less & & -.111 & .144 & .590 & 1 & .443 & .895 & .675 & & 1.187 & \\
\hline & Eque & (Ref) & $0^{\mathrm{b}}$ &. & 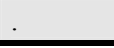 & 0 & & . & & & . & \\
\hline & & Intercept & & -.187 & .896 & & 44 & 1 & .835 & & & \\
\hline & & Age of the women & & -.016 & .008 & & 563 & 1 & .059 & .984 & .969 & 1.001 \\
\hline & & Family size & & -.029 & .022 & & 656 & 1 & .198 & .972 & .931 & 1.015 \\
\hline & & $\begin{array}{l}\text { Age marriage } \\
\text { Place of residence }\end{array}$ & & .026 & .007 & & .963 & 1 & $.000^{*}$ & 1.026 & 1.012 & 1.040 \\
\hline & & Rural & & .001 & .090 & & 00 & 1 & .988 & 1.001 & .840 & 1.194 \\
\hline & & Urban (Ref) & & $0^{\mathrm{b}}$ & . & & & 0 & . & . & . & . \\
\hline & & Justification of beating & & & & & & & & & & \\
\hline & & No & & 1.223 & .193 & & .011 & 1 & $.000^{*}$ & 3.396 & 2.325 & 4.961 \\
\hline & & Yes (Ref) & & $0^{\mathrm{b}}$ & . & 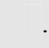 & & 0 & . & & . & . \\
\hline Women a & & Women's educational status & & & & & & & & & & \\
\hline husband/ & rtner & No education & & -.433 & .179 & & 849 & 1 & $.016^{*}$ & 649 & .457 & .921 \\
\hline & & Primary & & -.216 & .174 & & 550 & 1 & .213 & .806 & .573 & 1.132 \\
\hline & & $\begin{array}{l}\text { Secondary and above (Ref) } \\
\text { Access to media }\end{array}$ & & $0^{\mathrm{b}}$ & . & & & 0 & & & & \\
\hline & & Yes & & 2.790 & .813 & & .772 & 1 & $.001 *$ & 16.273 & 3.307 & 80.079 \\
\hline & & Sometimes & & 2.091 & .847 & & 093 & 1 & $.014 *$ & 8.089 & 1.538 & 42.544 \\
\hline & & Not at all (Ref) & & $0^{\mathrm{b}}$ & . & & & 0 & . & & . & . \\
\hline & & Women's Wealth index & & & & & & & & & & \\
\hline & & Rich & & -.320 & .069 & & .370 & 1 & $.000^{*}$ & .726 & .634 & .831 \\
\hline & & Medium & & -.066 & .068 & & & 1 & .328 & .936 & .819 & 1.069 \\
\hline & & Poor (Ref) & & $0^{\mathrm{b}}$ & - & & & 0 & . & 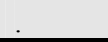 & . & \\
\hline
\end{tabular}




\begin{tabular}{|c|c|c|c|c|c|c|c|c|}
\hline Educational status of Husband/partner & & & & & & & & \\
\hline No education & .103 & .125 & .671 & 1 & .413 & 1.108 & .867 & 1.417 \\
\hline Primary & .137 & .123 & 1.242 & 1 & .265 & 1.146 & .902 & 1.458 \\
\hline $\begin{array}{l}\text { Secondary and above a (Ref) } \\
\text { Women's employment status }\end{array}$ & $0^{\mathrm{b}}$ & . & & 0 & . & & & . \\
\hline No & -.007 & .065 & .012 & 1 & .912 & .993 & .873 & 1.129 \\
\hline Yes (Ref) & $0^{\mathrm{b}}$ & . & & 0 & . & . & & . \\
\hline Women's income relative to her husband & & & & & & & & \\
\hline Greater & -.336 & .106 & 10.139 & 1 & $.001 *$ & .714 & .581 & .879 \\
\hline Less & -.239 & .111 & 4.658 & 1 & $.031 *$ & .788 & .634 & .978 \\
\hline Equal (Ref) & $0^{\mathrm{b}}$ & & & 0 & & & & \\
\hline
\end{tabular}

The reference category is: Husband/partner alone. *Significance at $5 \%$. Ref $=$ Reference

\section{Conclusion and Recommendation}

\subsection{Conclusion}

In this study, a woman's level of education, her employment status, Income, media exposure, place of residence, age at marriage, family size and attitude towards wife beating are found to be determinants of empowerment; which is consistent result with the study by (Mason, 2006; and Kishor, 2005).

Employment is one aspect of social life in which gender roles and relationships emerge. Employment can be a source of empowerment for both women and men, especially if they are in control of the income they generate. In this study respondents were asked whether they are employed at the time of the survey. While employment can play an important role in the process of improving women's empowerment in the study area, there are numerous barriers to overcome, and employment, even under all the right conditions. In order for employment to be more empowering to women, the structural barriers to women's rights and equality must be addressed in the household, the community, the state, the nation and around the globe.

Result of this study show that women whose cash earnings exceed their husbands' are more likely to report that they themselves decide how their husbands' earning are used than are those who earn less than their husbands or those who earn the same as their husbands. Women who earn the same as their husbands are the most likely to report that decisions on the use of their husbands' earnings are mainly made jointly with their husbands. Thirty-Four percent of women who earn less their husbands say that their husbands decide on the use of their earnings.

The likelihood that a currently married woman is the main decision-maker regarding the use of her cash earnings increases with the number of children the woman has. This suggests that women who have more children are more empowered than women with fewer or no children. The table also reveals that older women and women in the highest wealth quintile are more likely than other women to decide by themselves on how their cash earnings are used. Women in urban areas are more likely than women in rural areas to make independent decisions about the use of the money they earn. In contrast, in both rural and urban areas about the same proportions of currently married women make joint decisions with their husbands.

Decision-making can be a complex process, and the ability of women to make decisions that affect the circumstances of their own lives an essential aspect of their empowerment. In order to assess women's decision-making autonomy, this study collected information on women's participation in three types of household decisions: respondent's own health care, making major household purchases, and visits to family or relatives. The study shows the percent distribution of currently married women according to the person in the household who usually makes decisions concerning these matters.

Twelve percent of currently married women make their own decisions on their own health care, while one woman of every four said that her husband mainly makes such decisions. Decisions on large household purchases are most likely to be made jointly by wife and husband (48 percent), while for almost half that percentage (43 percent) the husband alone mainly makes those decisions. Only 3 percent of women make these decisions by themselves.

Urban women and women who are in the highest wealth quintile are more likely to participate in decision-making than rural women and those in lower wealth quintiles. Similarly, women who are employed for cash are more likely than women not employed or not employed for cash to participate in decision-making.

All violence against women has serious consequences for their mental and physical wellbeing, including their reproductive and sexual health (WHO, 1999). Wife beating is a form of physical violence that particularly degrades women. It is also a violation of women's human rights.

Worldwide, abuse by a husband is one of the most common forms of violence against women (Heise et al., 1999). Acceptance of wife beating practice reflects women's low status and the perception that men are superior to women. In addition to adverse physical health outcomes, this form of violence lowers a woman's self-esteem and her image in society, leading to her disempowerment. Domestic violence is common in Ethiopia, in both urban and rural families. When a society tolerates and accepts violence against women, its eradication is more difficult. The Government of Ethiopia revised its family law in 2000 and its criminal law in 2005 to protect the rights of women and children and to promote gender equality and equity.

Women who believe that a husband is justified in hitting or beating his wife may believe themselves to be of low status. 
Such a perception could act as a barrier to accessing health care for themselves and their children, affect their attitude towards contraceptive use, and damage their general wellbeing.

This study gathered information on attitudes towards wife beating. Women and men were asked whether a husband is justified in beating his wife in various circumstances: if the wife burns the food, argues with him, goes out without telling him, neglects the children, or refuses sexual intercourse with him.

The acceptance of wife beating inversely correlates with education and wealth. Women with no education are more than three times as likely as women with more than secondary education to agree with at least one specified justification for wife beating. As was observed for female respondents, men living in rural areas are more likely than men living in urban areas to accept wife beating.

\subsection{Recommendation}

Low status characterizes virtually every aspect of girls' and women's lives. Given the heavy workload imposed on girls at an early age, early marriage without choice, and a subservient role to both husband and mother-in-law, girls and women are left with few opportunities to make and act on their own decisions. Women's status, including family and community roles, profoundly influences their ability to make decisions about their own health care and childbearing, which, in turn, affects their vulnerability to illness and HIV/AIDS.

Gender responsive programs should recognize that practices such as FGC, early marriage, abduction, rape, lack of access to and control over resources, and the absence of decisionmaking and negotiation power all negatively affect women's reproductive health and rights. Because many women have limited control over their sexual lives and contraceptive use, integrating gender issues into reproductive health and HIV/AIDS program interventions becomes critical. Active male involvement in reproductive and family care-giving enhances responsible parenthood and reduces gender based violence that affects women's reproductive health and rights.

To accelerate the process of gender equality, more work has to be done to provide women with access to education and information. Women and girls continue to need economic support, as poverty exacerbates their isolation, and earning power enhances their community and family status. Progress also demands that entire communities take individual and collective measures against gender-based violence and harmful traditional practices. Developing widespread communications and harnessing innovative media techniques, when linked to scaling up these interventions, will enable us to reach even more women and girls across the country.

The Ethiopian government is trying to change women's condition through crafting, adopting and implementing various policies that are assumed to alleviate women's subordination, discrimination and poverty. The country has also adopted global agreements and conventions like the Convention on Elimination of all forms of Discrimination against Women (CEDAW) and Millennium Development Goal (MGD). The focus of the government and its allies as a whole is therefore the issue of gender equality and women's empowerment.

Despite, the commitment and effort of inclusion of women to the development process, the practical women's problem on the ground is still untouched. As can be seen from the analysis, poor women even trying to empower by their effort are tumbled by institutionalized barriers. As a result, women could not bring significant change in the existing unequal power relation, though they proved that they can change the dominant discourse as they are able to do what men were expected to do in the traditional society.

But still they are submissive to the existing gender role because of lack of appropriate development intervention. Therefore, the policy designed at the macro level should be translated to solve the problem on the ground. Thus, considering their agency, women's empowerment at different levels might be realized. On the other hand, collecting clear statistical data and studying the different types of women's home based work and their empowerment and/or disempowerment effect might be areas of research that further have policy implications.

\section{References}

[1] Adanech K, Azeb T (1991). Gender Influence on Women's Health: A Review of the Ethiopian Situation.

[2] Tsehai Berhane Selassie (ed.) Gender Issues in Ethiopia. Institute of Ethiopian Studies.

[3] Addis Ababa University, Addis Ababa.

[4] Almaz E (1991). Perspectives on Gender and Development.

[5] Tsehai Berhane Selassie (Ed.) Gender Issues in Ethiopia. Institute of Ethiopian Studies. Addis Ababa University, Addis Ababa.

[6] CSA (2004). Urban Bi-Annual Employment Unemployment Survey, Addis Ababa.

[7] FDRE (1995). Education and Training Policy. Addis Ababa: St. Goerge Printing Press.

[8] FDRE (1997). Constitution. Addis Ababa: Berhanena Selam Printing Enterprise.

[9] Kishor, S. (ed) A Focus on Gender: Collected Papers on Gender Using DHS Data. Calverton, Maryland, USA: ORC Macro.

[10] Hirut T (2004). Violence Against Women in Ethiopia: A Strong Case of Civil Society Concern.

[11] Kishor S (ed) (2005). A Focus on Gender: Collected Papers on Gender Using DHS Data. Calverton, Maryland, USA: ORC Macro.

[12] Mason KO (1986). The status of women: conceptual and methodological issues in demographic studies. Sociological Forum, 1 (2): 284-300.

[13] Mukuria A, Aboulfia C, Themme A (2005). The Context of Women's Health: Results from the Demographic and Health Surveys, 1994 - 2001. Comparative Reports No 11. Calverton, Maryland. 